\title{
An Analysis of Green Building Design Elements Appearing in Ideal Housing Drawings Made by University Students in Korea
}

\author{
Min-Ah Lee ${ }^{1}$, Bok-Hee Yoo ${ }^{2}$ \\ ${ }^{1}$ Kunsan National University \\ Jeonbuk, City of Kunsan, Korea \\ leema@kunsan.ac.kr \\ ${ }^{2}$ Ulsan University \\ City of Ulsan, Korea \\ yoobk@ulsan.ac.kr
}

\section{Extended Abstract}

The aim of this study was to analyze the green building design elements in ideal housing plans formulated by university students in Korea, with consideration for popularization of the national green building policy.

Data were collected from two universities (K and U Universities) in Korea during the 2017 spring semester; 110 students taking the liberal arts class were required to plan and draw their ideal housing environments. Ultimately, 107 cases were used for the analysis, which was based on seven categories for [1]Korean green building certification; 96 students included green building design elements in their plans, though none addressed water circulation management.

Of the other six categories, ecological environments were applied most commonly in the drawings(70.8\%), followed by indoor environment(49.0\%), land use/transportation(41.7\%), housing efficiency(18.8\%), energy/environmental pollution(14.6\%), and materials/resources(10.4\%). A chi-square analysis was performed to investigate differences among students' characteristics. Those living in detached houses or multi-family housing focused on land use/transportation $\left(\chi^{2}=6.250, \mathrm{p}<.05\right)$; students with more than five family members focused on energy/environmental pollution $(\mathrm{p}<.05)$. On the other hand, materials/resources were stressed by students living in or formerly living in dormitories $(\mathrm{p}<.01 ; \mathrm{p}<.05)$.Female students were more interested in indoor environments, in contrast to males $\left(\chi^{2}=6.741\right.$, $\mathrm{p}<.01)$. Contents of the drawings were investigated in detail. Students drew ecological environments in complexes or on residential land predominantly, emphasizing gardening, green roofs/walls, and water spaces(67cases). For indoor environments, they mainly drew large windows for natural light(34cases), followed by soundproof construction/equipment(9cases), air pollution control(9cases), and natural ventilation(7cases). Regarding land use/transportation, convenient walking access to living facilities to decrease traffic loads were mostly expressed(32cases), followed by housing site development and the use of geographical features(12cases), proximity to public transportation(8cases), and bicycle trail/racks(4cases). For housing efficiency, 10cases involved safety (e.g., security systems), disaster prevention and response (e.g., escape equipment). Residential community facilities(6cases), spatial flexibility(3cases), and home networks(2cases) were also cited. Utilization of new generation energy such as sunlight, solar heat, and geothermal heat (10cases) and improvements for energy efficiency(e.g., triple-glazed windows or thick walls) were named as energy/environmental concerns. For materials/resources, the use of recycled materials(6cases), certified products(2cases) and recycling storage facilities (2cases) were mentioned.

Results indicate that students perceived green building design environments as green environments and prefer to use equipment that promotes good health and moods, such as natural lights. Such ideals differ somewhat from the direction of the national green building policy that aims to decrease usage of carbon materials and pollutants and encourage use of new generation energy in construction process. A counter plan is required to make people aware of the seriousness of the energy crisis and the necessity of using low carbon materials and resources routinely.

\section{References}

[1] KEITI (2016, September 01), G-Seed. [Online]. Available: https://www.gbc.re.kr/index.do 